\title{
Is Endoscopic Band Ligation of Esophageal Varices Contraindicated in Child-Pugh C Patients?
}

Introduced by Van Stiegmann in 1986 (1), endoscopic band ligation of esophageal varices (EBLEV) has been accepted as an alternative method to conventional sclerotherapy (CS), given its simplicity, efficacy, and low morbidity rate $(2,3)$. Nevertheless, of the first thirty of our patients who underwent this procedure from January 1992 to June 1992, early and severe rebleeding episodes occurred in four $(13.3 \%)$. All these patients were part of a protocol comparing EBLEV with CS (intravariceal injection of $3 \%$ ethanolamine-glucose solution). All patients had previously had at least one episode of bleeding.
The four patients with rebleeding included two males and two females aged between 45 and 77 years, with a mean age of 57 years. Portal hypertension was secondary to alcoholic cirrhosis in two, post hepatitis cirrhosis in one, and drug-induced (alphamethyl-dopa) cirrhosis in one patient. All patients belonged to the Child-Pugh $\mathrm{C}$ group (out of a total of eight patients from the study group with Child-Pugh C classification - $50 \%$ ).

The hemorrhagic episodes occurred within seven days of the first endoscopic band ligation session. The exact bleeding site could be identified in all patients - there was an ulcer over the varix at the 
original site of band ligation. Despite all efforts to arrest hemorrhage using CS and balloon tamponade, two patients died (mortality $6.6 \%$ ).

This is probably attributable to a severe disturbance of hepatic function, such as a primary alteration of coagulation factors, associated with delayed healing due to inadequate protein (fibroblast) synthesis, which is necessary for the healing process (4). At present, the use of cyanoacrylate glue would be a better option in patients in the Child-Pugh C group, because its success in preventing rebleeding is independent of the above-mentioned factors (5).

Based on the events reported above, we consider that when patients are in the Child-Pugh C group, it is a contraindication for EBLEV. In our opinion, the real impact and limitations of this new method need to be defined further.

\section{P. Sakai, F. Maluf Filho, J. M. Melo, S. Ishioka}

Gastrointestinal Endoscopy Unit of the Hospital das Clinicas of São Paolo, Brazil

\section{References}

1 Stiegmann $G$ van, Cambre T, Sun JH: A new endoscopic elastic band ligation device. Gastrointest. Endosc. 1986; 32: 230-233.

2 Goff JS, Reveille RM, Stiegmann GV: Endoscopic sclerotherapy versus endoscopic variceal ligation: esophageal symptoms, complications and mortality. Am. J. Gastroenterol. 1988; 83: 1240-1244.

3 Stiegmann GV, Goff JS, Sun JH, Lowenstein SR: Endoscopic sclerotherapy as compared with endoscopic ligation of bleeding esophageal varices. N. Engl. J. Med. 1992; 326: 1527-1532.

4 Sakai P, Boaventura S, Capacci ML, et al.: Endoscopic sclerotherapy of bleeding esophageal varices: a comparative study of results in patients with schistosomiasis and cirrhosis. Endoscopy 1988; 20: 134-136.

5 Maydeo AP, Soehendra N: Therapeutic approach in patients with oesophageal bleeding varices recalcitrant to sclerotherapy. In: Dobrilla G, Bardhan KD, Steele A (eds): Non-responders in gastroenterology. New York: Raven Press, 1991: 45-68.

Corresponding Author

P. Sakai, M.D.

Rua João Julio 331

CEP 01323-020, São Paulo

Brazil 